\title{
Preparation of Surface-Modified Nanocellulose from Sugarcane Bagasse by Concurrent Oxalic Acid-Catalyzed Reactions
}

\author{
Arisara Sriruangrungkamol ${ }^{1}$, Thipsirin Wongjaiyen ${ }^{1}$, \\ Witold Brostow ${ }^{2}$, and Wunpen Chonkaew ${ }^{1 *}$
}

\begin{abstract}
${ }^{1}$ Department of Chemistry, Faculty of Science, King Mongkut's University of Technology Thonburi, Bangkok 10140, Thailand

${ }^{2}$ Laboratory of Advanced Polymers and Optimized Materials (LAPOM), Department of Materials Science \& Engineering, University of North Texas, TX 76207, USA
\end{abstract}

*Corresponding author. E-mail: wunpen.cho@mail.kmutt.ac.th https://doi.org/10.12982/CMUJNS.2020.0065

Received: March 3, 2020

Revised: April 29, 2020

Accepted: May 8, 2020

\section{ABSTRACT}

Concurrent oxalic acid-catalyzed reactions, including cellulose hydrolysis and esterification of the hydrolyzed cellulose, were performed to prepare the nanocellulose from sugarcane bagasse. Hydrothermal hydrolysis at $100^{\circ} \mathrm{C}$ in a microwave digester was performed using oxalic acid at the concentrations of $0,5,10$, and $30 \% \mathrm{w} / v$ as catalysts. The hydrolyzed cellulose so obtained was characterized by several techniques, including FTIR, TGA, $X R D$, and viscosity measurements. The concentration of oxalic acid slightly affects the thermal stability, crystallinity, and molecular weight of the hydrolyzed cellulose. Apart from acting as a catalyst, oxalic acid at 10 or $30 \%$ w/v could react with $\mathrm{OH}$ groups of the cellulose by esterification. After mechanical homogenization, microfibrils of hydrolyzed cellulose were separated. The SEM results show a web-like network structure of the mixture of cellulose fibrils (CNFs) and fibril aggregates-indicating the nanofiber form of nanocellulose. The dispersion stability of the suspensions in deionized water and organic solvents (dimethyl formamide (DMF) and acetone) increases with increasing concentration of oxalic acid for hydrolysis-as seen in the presence of oxalate groups on the surfaces of CNFs. Thus, the microwaveassisted oxalic acid hydrolysis, followed by the homogenization of cellulose provides a potential method for the production of surface-modified CNFs.

Keywords: Oxalic acid-catalyzed reactions, Nanocellulose, Nanofibers 


\section{INTRODUCTION}

Production of nanocellulose becomes increasingly important since it is an environmentally friendly material-with potential applications as a reinforcement for nanocomposites, a thickening agent for food and cosmetics, a releasing agent for drug delivery, and a substrate for the optical devices. Reinforcements are essential when a polymeric matrix is desired, while higher mechanical strength than in neat polymers is required (Brostow and Hagg Lobland, 2017).

Nanocellulose can be extracted from bioresources and agricultural waste products such as straws, cotton linter, and bagasse. Bagasse is a sugar cane fiber waste left from juice extraction, a by-product of the sugar refining industry. Bagasse is composed of $40-50 \%$ of cellulose, $25-35 \%$ of hemicelluloses, $18-24 \%$ of lignin, 1-4\% of ash, and less than 1\% minerals and wax (Mandal et al., 2011). Different methods have been reported for nanocellulose extraction, such as mechanical ones (Lee et al., 2009; Li et al., 2012; Wang et al., 2015), steam explosion (Cherian et al., 2010; Deepa et al., 2011), chemical hydrolysis (Hafraoui et al., 2008; Lu et al., 2013; Liu et al., 2014; Pereira et al., 2014; Espinosa et al., 2013; Soni et al., 2015; Zeniet al., 2015) and enzyme-assisted hydrolysis (Cui et al., 2016), as well as combinations of these approaches (Abraham et al., 2013; Chimentão et al., 2014).

As for the chemical method, the acid hydrolysis is considered a popular method for the isolation of nanocellulose from cellulose (Lui et al., 2014). The most frequently used acids are mineral acids, including sulfuric $\left(\mathrm{H}_{2} \mathrm{SO}_{4}\right)$, hydrochloric $(\mathrm{HCl})$, and phosphoric $\left(\mathrm{H}_{3} \mathrm{PO}_{4}\right)$. Nanocellulose obtained from the reaction with $\mathrm{H}_{2} \mathrm{SO}_{4}$ has negatively charged surfaces, but no charge was found on the surfaces of the fibers obtained with $\mathrm{HCl}$ (Hafraoui et al., 2008). Due to the repulsion between the ionic charges on the surface, the dispersibility of the nanocellulose obtained from the $\mathrm{H}_{2} \mathrm{SO}_{4}$ hydrolysis was better than for nanocellulose prepared from the $\mathrm{HCl}$ hydrolysis (Hafraoui et al., 2008). However, nanocellulose prepared from $\mathrm{H}_{2} \mathrm{SO}_{4}$ hydrolysis has much lower thermal stability than that prepared from $\mathrm{HCl}$ hydrolysis (Zeni et al., 2015). Some approaches used the $\mathrm{HCl}+\mathrm{H}_{2} \mathrm{SO}_{4}$ mixtures for hydrolysis of cellulose, but higher thermal stability was achieved at the expense of worse dispersion (Espinosa et al., 2013). Phosphoric acid was reported to provide both good dispersibility and relatively high thermal stability (Espinosa et al., 2013). Although the uses of the mineral acids as catalysts for hydrolysis are simple and give a reasonable yield, those acids have aggressive vapors, are highly corrosive to the equipment, and they generate large amounts of waste. Given the environmental concerns, the substitution of the concentrated liquid mineral acid by a solid acid (e.g., phosphotungstenic acid) (Lui et al., 2014) was proposed; however, longer 
hydrolysis times due to limited contact between solid and liquid would be a problem.

Mechanical processes such as high-pressure homogenization, ultrasonication, cryo crushing, and microfluidization, involve a high energy consumption needed to disintegrate the cellulose microfibrils (Ferrer et al., 2012; Masruchin et al., 2015; Soni et al., 2015). Steam explosion treatment and chemical pretreatment such as oxidation basic-acid hydrolysis followed by a mechanical treatment can decrease the energy consumption ( $\mathrm{Lu}$ et al., 2010; Lu et al., 2013; Li et al., 2015; Dahlem et al., 2019). Moreover, such pretreatments might minimize the sizes of the cellulose fibers, thus avoiding clogging of the homogenizer ( $\mathrm{Li}$ et al., 2012). Hydrolysis with milder organic acids, such as formic acid, has been reported for cellulose pretreatment before the mechanical treatment for nanocellulose production (Li et al., 2015; Du et al., 2016; Liu et al., 2016; Lv et al., 2019).

Oxalic acid, the strongest organic acid found, is a dicarboxylic acid with $\mathrm{pK}_{\mathrm{a} 1}=1.27$ and $\mathrm{pK}_{\mathrm{a} 2}=4.28$ (Lacerda et al., 2015). Oxalic acid has low toxicity in comparison to the common mineral acids such as $\mathrm{H}_{2} \mathrm{SO}_{4}$ and $\mathrm{HCl}$. It can be produced from the fermentation of natural biomass (Lacerda et al., 2015). Moreover, it is soluble in water and thus more efficient for hydrolysis of solid cellulose than those solid catalysts. Oxalic acid at high concentrations could precipitate as a pure solid. Thus, it can be easily recovered in solid form after reaction by distilling out the solvent and simple filtration (Lee et al., 2014). Lacerda et al. (2015) studied the performance of oxalic acid as a catalyst for the saccharification of cellulose pulp. They suggested that oxalic acid was a promising catalyst for the hydrolysis of cellulose for the production of sugars and pretreatment of the fibers before enzymatic hydrolyzes (Lacerda et al., 2015; Chen et al., 2016; Xu et al., 2017)

Given different methods of preparation, nanocellulose can be grouped into two classes, cellulose nanocrystals (CNCs) and cellulose nanofiber (CNFs). Cellulose nanofibers or microfibers (CNFs or CMFs) consisting of a mixture of fibril aggregates and cellulose fibrils with the width of 3-5 nm and the length of a few micrometers. (Lee et al., 2009; Li et al., 2012; Wang et al., 2015) could be obtained when using mild or enzymatic pretreatment followed by a mechanical treatment. CNC rod-like particles with the 3-5 nm width and 100-300 nm length can be prepared using strong acid hydrolysis (Hafraoui et al., 2008; Espinosa et al., 2013; Liu et al., 2014; Zeni et al., 2015). Ongthip and Chonkaew extracted CNFs from para-rubber sawdust using $\mathrm{H}_{2} \mathrm{SO}_{4}$ acid hydrolysis and following by high shear homogenization (Ongthip et al., 2018). The obtained CNFs with a diameter of $59.2 \mathrm{~nm}$ and several nm lengths.

In this work, we focus on the use of an organic acid as a catalyst in the hydrolysis of cellulose. We have used hydrothermal acid hydrolysis in a microwave reactor followed by mechanical homogenization to prepare CNFs 
from sugarcane bagasse. An environmental friendly acid, namely oxalic acid, was used for hydrolysis of cellulose before homogenization.

From our knowledge, there has been little work on the application of oxalic acid as a catalyst for hydrolysis of cellulose for the CNF production (Lu et al., 2010; Chen et al., 2012; Lu et al., 2013; Chimentão et al., 2014; Lacerda et al., 2015), but no work discussed the effects of the concentration of oxalic acid. It was found that the acid concentration was the significant effect for the nano/micro cellulose preparation (McCrackin et al., 1987; Kusumattaqiin et al., 2015; Liu et al., 2016). Thus, we have varied the concentration of oxalic acid at a constant temperature and fixed dwelling time in a microwave digester. Hydrolyzed cellulose obtained was characterized in terms of its yield, chemical structure, intrinsic viscosity, molecular weight, crystallinity, and thermal stability. The morphology and dispersion stability of the obtained nanocellulose fiber after mechanical homogenization, as well as creep property of nanocellulose films, were investigated.

\section{Materials}

\section{MATERIALS AND METHODS}

Sugarcane bagasse was collected in a local market (Nakhon, Pathom Province, Thailand). It was air-dried and chopped to small pieces with sizes of about $0.5-1 \mathrm{~cm}$. All sugarcane bagasse was milled and screened with a 500 mesh screen to get the fraction of bagasse with a size smaller than $25 \mathrm{~mm}$. Sodium hydroxide (Sigma Aldrich, USA), glacial acetic acid (100\%, Merck, USA), sodium chlorite (Sigma Aldrich, USA), ethanol (95\%, Merck, USA), oxalic acid (UNIVAR, Ajax Finechem Ltd, USA), dimethylformamide (DMF) and acetone (Merck, USA) were of analytical grade and used as received.

\section{Preparation of nanocellulose}

Firstly, cellulose was isolated from the bagasse using the alkaline hydrolysis technique modified from Sun et al. (2004). Briefly, the details were as follows. $20.0 \mathrm{~g}$ sugarcane bagasse was soaked in water at $70-80^{\circ} \mathrm{C}$ for $2 \mathrm{hr}$. Hemicellulose was extracted with $600 \mathrm{~mL}$ of $10 \%(\mathrm{w} / \mathrm{w})$ sodium hydroxide for 24 $\mathrm{hr}$ at room temperature. Bagasse was bleached, to remove a part of lignin and the residual hemicellulose, using $600 \mathrm{~mL}$ of $1.3 \%(\mathrm{w} / \mathrm{w})$ sodium chlorite. The solution was adjusted $\mathrm{pH}$ to 3.5-4.0 with the addition of glacial acetic acid, heated, and kept the temperature constant at $70^{\circ} \mathrm{C}$ for $2 \mathrm{hr}$. The insoluble residue was filtrated, washed with distilled water until the neutrality was attained, then washed with $95 \%$ ethanol and dried in the oven at $60^{\circ} \mathrm{C}$ for $3 \mathrm{hr}$. Bleached cellulose was hydrothermally hydrolyzed under microwave irradiation using oxalic acid as a catalyst. $1.0 \mathrm{~g}$ cellulose was mixed with $20 \mathrm{~mL}$ oxalic acid (OX) in a vessel and loaded to the microwave reactor (CEM Mars 5, 1,000 watts). The acid concentration was varied at $0,5 \%, 10 \%$ and $30 \%(\mathrm{w} / \mathrm{v})$. The samples were heated 
to $100^{\circ} \mathrm{C}$ with the ramp to the temperature of $5 \mathrm{~min}$ and stayed at $100^{\circ} \mathrm{C}$ for $1 \mathrm{~min}$ under the pressure of $800 \mathrm{psi}$. All experiments were carried out using a liquid/solid ratio of $20 \mathrm{~mL} / \mathrm{g}$ dry weight of bleached bagasse. Cold deionized water was added into the solution to quench the reaction, and the $\mathrm{pH}$ was adjusted with $1 \%(\mathrm{w} / \mathrm{v})$ sodium hydroxide until the solution was neutral. The obtained products after hydrothermal hydrolysis were named as hydrolyzed cellulose (HC). HC was filtrated and soaked in the deionized water overnight to remove the excess oxalic acid, then filtrated, and dried in the oven at $60{ }^{\circ} \mathrm{C}$ for $3 \mathrm{hr}$. The $\%$ yield of $\mathrm{HC}$ was calculated as follows:

$$
\% \text { yield }=\left[\frac{(\text { mass of hydrolyed cellulose })}{(\text { mass of cellulose })}\right] \times 100
$$

To prepare cellulose nanofiber (CNFs), HC was mechanically disintegrated in deionized water using a homogenizer (Ultra-Turrax T25 Homogenizer, IKA, USA) at $11,000 \mathrm{rpm}$ for $10 \mathrm{~min}$ in an ice bath. The final concentration of the obtained nanocellulose suspension was about $10 \mathrm{mg} / \mathrm{mL}$.

The CNF films were prepared using solution casting. The solid content of CNF suspension after mechanical homogenizer was adjusted to $0.5 \% \mathrm{w} / \mathrm{w}$. The suspension was then poured into the petri dish and dried in air for $7 \mathrm{~d}$ at ambient condition. The films with a thickness of $0.20 \mathrm{~mm}$ were obtained.

\section{Characterization}

FTIR spectra were obtained using a Fourier transform infrared spectrometer (Nicolet 6700, Thermo Scientific, Canada). Each sample (approximately $1 \mathrm{mg}$ ) was blended with $100 \mathrm{mg} \mathrm{KBr}$ powder and compressed with the pressure of $9 \mathrm{~N}$ to form a disc. The spectra were recorded from $4,000 \mathrm{~cm}^{-1}$ to $500 \mathrm{~cm}^{-1}$ using 32 scans with a resolution of $1 \mathrm{~cm}^{-1}$.

To understand effects of oxalic acid used in the hydrothermal hydrolysis, crystallinity, thermal stabilities of hydrolyzed cellulose, and morphology of nanocellulose were investigated using $\mathrm{X}$-ray diffractometry, thermogravimetric analysis (TGA) and scanning electron microscopy (SEM), respectively.

XRD patterns were recorded using an X-ray diffractometer (Miniflex, Rigaku, Japan) with $\mathrm{CuK \alpha}$ radiation source. The scattering angle range was $5-60$ - with a scanning rate of $0.03 \% / \mathrm{min}$. The crystallinity index (CrI) was calculated according to Sega et al. (1959) as

$$
\% \operatorname{CrI}=\left[1-\frac{(\operatorname{Iam})}{(I 200)}\right] \times 100
$$


where $I_{200}$ is the maximum peak intensity of the (200) diffraction plane and $I_{a m}$ is the intensity of the amorphous peak at the minimal depression (where $2 \theta=18.5$ )

Crystallite size was estimated (Liu et al., 2014) as:

$$
t_{h k l}=\left[\frac{(0.9 \lambda)}{\beta_{1 / 2} \cos \theta}\right]
$$

where $t_{\text {hkl }}$ is the crystal sizes in the direction normal to the diffraction plane $h k l$, $\lambda$ is the wavelength of a X-ray source ( $1.54 \AA$ for $\mathrm{CuK} \alpha)$, and $\beta_{1 / 2}$ is the full width at half maximum (FWHM) of the diffraction peaks.

The average molecular weight of the bleach cellulose and cellulose nanofiber $(\mathrm{CN})$ obtained from the homogenization of the hydrolyze cellulose was determined by viscosity method. $0.25 \mathrm{~g}$ of Cellulose nanofiber sample was dissolved in $20 \mathrm{~mL}$ of $\mathrm{N}, \mathrm{N}$-dimethylacetamide (DMAc), and heated until $100{ }^{\circ} \mathrm{C}$ for $30 \mathrm{~min} .0 .40 \mathrm{~g}$ of $\mathrm{LiCl}$ was then poured into DMAc solution and further heated for $1 \mathrm{hr}$. A series of cellulose solutions with concentration of $0.1,0.2,0.4$ and $0.8 \%(\mathrm{w} / \mathrm{v})$ in $2.0 \%(\mathrm{w} / \mathrm{w}) \mathrm{LiCl} / \mathrm{DMAc}$ were then prepared. The viscosity measurement was performed at $30^{\circ} \mathrm{C}$ using a Ubbelohde viscometer. The viscometer was clamped to a holder and suspended in a water bath. $20 \mathrm{~mL}$ sample was pipetted into the viscometer for each determination time to flow from one mark to another was measured. Five flow time measurements were carried out. The average value of time to flow for each sample concentration was calculated and reported.

Thermal stabilities of sugarcane bagasse (SCB) and hydrolyzed cellulose (HC) were determined using TGA (Pyris1TGA, Perkin Elmer, USA). Approximately $8 \mathrm{mg}$ of each dried samples was loaded into an aluminum pan and heated from $30^{\circ} \mathrm{C}$ to $750^{\circ} \mathrm{C}$ with a heating rate of $10^{\circ} \mathrm{C} / \mathrm{min}$. All experiments were performed under a nitrogen atmosphere, with a gas flow of $20 \mathrm{~mL} / \mathrm{min}$.

The morphology of nanocellulose samples obtained after mechanical homogenization was studied using a Field Emission- Scanning electron microscope (FE-SEM, NanoSEM450, Nova, USA) with an accelerating voltage of $5.0 \mathrm{kV}$. The surfaces of the nanocellulose samples were coated with gold under vacuum before observation.

\section{Dispersion studies}

The dispersibility of nanocellulose suspension was studied by observing the stability of dispersion in water, acetone, and DMF as a function of time. Each sample was prepared using a concentration of $10 \mathrm{mg} / \mathrm{L}$. The nanocellulose dispersion was observed immediately after the homogenization process $(0 \mathrm{hr})$, and subsequently after $1 \mathrm{~d}, 3 \mathrm{~d}, 5 \mathrm{~d}$, and $7 \mathrm{~d}$. 


\section{Creep test}

Creep test under dynamic mechanical analyzer equipped with tension fixture (DMA1, Mettler Toledo, Switzerland) was carried out. A constant load at $3.0 \mathrm{~N}$ was applied to the nanocellulose films, and the displacement was measured at $25^{\circ} \mathrm{C}$.

\section{RESULTS}

\section{FTIR analysis}

Figure 1 shows FTIR spectra of cellulosic fibers from sugarcane bagasse (SCB) at different treatment stages, including untreated SCB fibers, bleached cellulose, and hydrolyzed cellulose (HC). All studied fibers demonstrated similar characteristic peaks approximately at 2,910, 1,640, 1,430, 1,324, 1,062, and 895 $\mathrm{cm}^{-1}$. Besides, the absorption band between 3,000 and 3,600 $\mathrm{cm}^{-1}$ was observed in all types of fibers. However, those absorption peaks at 1,730, 1,600, 1,241, and $1,515 \mathrm{~cm}^{-1}$, which found in SCB fiber, were disappeared after the alkaline treatment and bleaching process. After hydrothermal hydrolysis with $10 \%$ and $30 \%(\mathrm{w} / \mathrm{v})$ oxalic acid $(\mathrm{OX})$ in microwave reactor, the peak at $1,730 \mathrm{~cm}^{-1}$ was observed again.

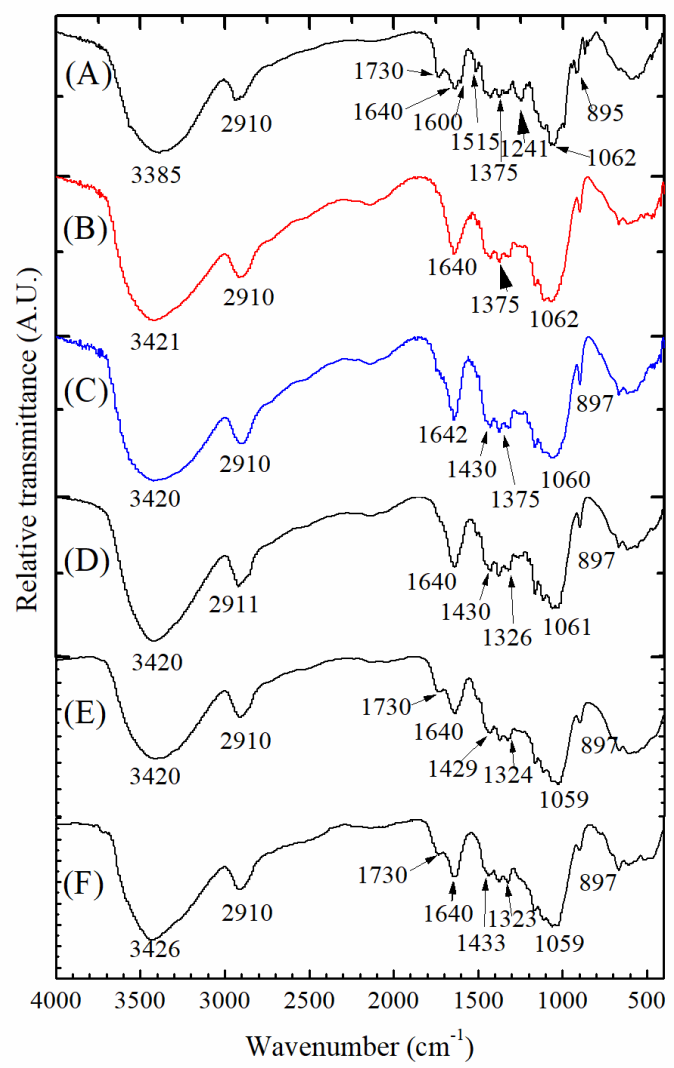

Figure 1. FTIR spectra of: (A) SCB; (B) bleached cellulose; cellulose hydrolyzed with: (C) 0\% (w/v) OX; (D) 5\% (w/v) OX; (E) 10\% (w/v) OX; and (F) 30\% (w/v) OX. 


\section{$\%$ Yield and viscosity average molecular weight}

The experimental yields of the hydrolyzed cellulose obtained from hydrothermal hydrolysis at $100^{\circ} \mathrm{C}$ in a microwave digester using oxalic acid at the concentrations of $0,5,10$, and $30 \% \mathrm{w} / \mathrm{v}$ as catalysts were $84.2 \pm 1.2,75.0 \pm 1.0$, $60.5 \pm 0.4$ and $52.9 \pm 1.7$, respectively.

The intrinsic viscosity [ $\eta]$ and average molecular weight based on viscosity measurement $\bar{M}_{V}$ of bleached cellulose and celluloses fiber are listed in Table 1. The viscosity average molecular weight, $\bar{M}_{V}$, of the bleach cellulose was $3.19 \times 10^{6}$. It was found that those hydrolyzed cellulose fibers prepared by hydrothermal hydrolysis with various concentrations of oxalic acid and followed by mechanical homogenization were two order of magnitude lower than that of the bleach fibers.

Table 1. The intrinsic viscosity ([ๆ]) and viscosity average molecular weight $\bar{M}_{V}$ of the bleached cellulose, and hydrolyzed celluloses fiber obtained from hydrothermal hydrolysis with various concentrations of oxalic acid $(\%(w / v)$ OX) and followed by mechanical homogenization.

\begin{tabular}{cccccc}
\hline Samples & $\begin{array}{c}\text { Bleached } \\
\text { cellulose }\end{array}$ & HC-0\%OX & HC-5\%OX & HC-10\%OX & HC-30\%OX \\
\hline$[\boldsymbol{\eta}]$ & 453 & 30.2 & 26.7 & 16.2 & 15.4 \\
$\overline{\boldsymbol{M}}_{\boldsymbol{V}}$ & $3.19 \times 10^{6}$ & $3.78 \times 10^{4}$ & $2.92 \times 10^{4}$ & $1.94 \times 10^{4}$ & $1.86 \times 10^{4}$ \\
\hline
\end{tabular}

\section{X-ray diffraction}

The XRD patterns of raw SCB, bleached cellulose, and hydrolyzed celluloses (HC) are shown in Figure 2. The XRD pattern of raw SCB fiber shows several diffraction peaks embedded in the amorphous halo. The more ordered structure with the XRD pattern at $2 \theta=16.6^{\circ}, 22.2^{\circ}$ and $34.8^{\circ}$ was observed in the bleached cellulose and the hydrolyzed cellulose. With higher concentration of the oxalic acid used in the hydrolysis, the XRD peak intensity was found to increase. 


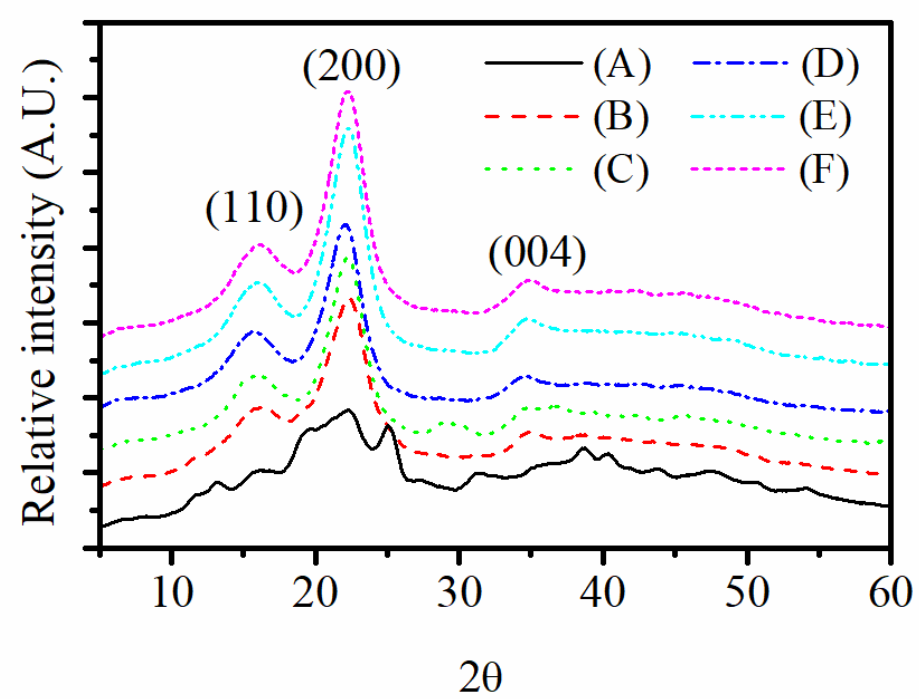

Figure 2. X-ray diffractograms of: (A) SCB; (B) bleached cellulose; hydrolyzed cellulose obtained by hydrothermal hydrolysis with (C) $0 \%(\mathrm{w} / \mathrm{v}) \mathrm{OX}$; (D) $5 \%(\mathrm{w} / \mathrm{v})$ OX; (E) $10 \%(\mathrm{w} / \mathrm{v})$ OX and (F) $30 \%(\mathrm{w} / \mathrm{v})$ OX.

\section{Thermogravimetric analysis}

Thermal stabilities of the prepared samples were evaluated by TGA at a heating rate of $10^{\circ} \mathrm{C} / \mathrm{min}$ for $\mathrm{SCB}$, bleached cellulose, and the cellulose hydrothermally hydrolyzed with $0,5,10,30 \%(\mathrm{w} / \mathrm{v})$ oxalic acid; see Figure 3. Thermal degradation temperature $\left(\mathrm{T}_{\mathrm{d}}\right)$ is defined as the onset temperature for degradation while the maximum degradation temperature $\left(\mathrm{T}_{\max }\right)$ is obtained from the derivative weight (DTG) curves as the temperature at which the degradation rate is fastest. The values are listed Table 2. 
(a)

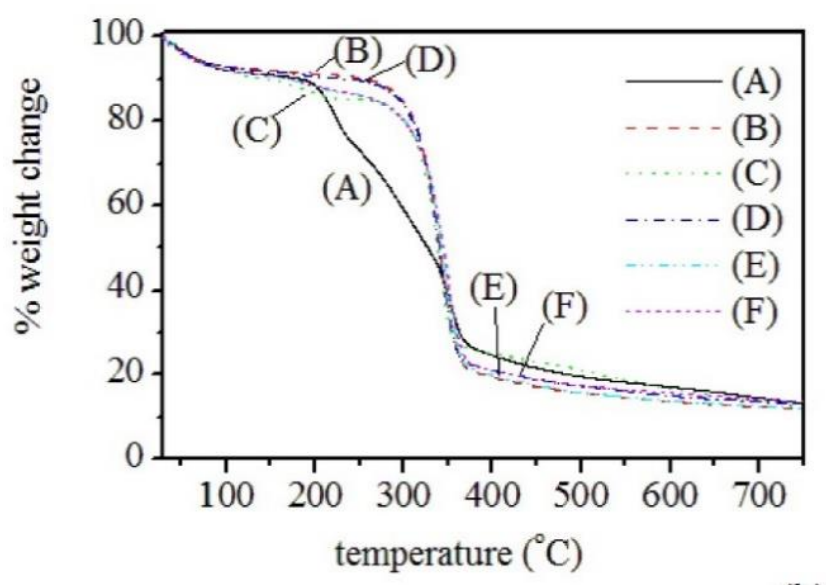

(b)

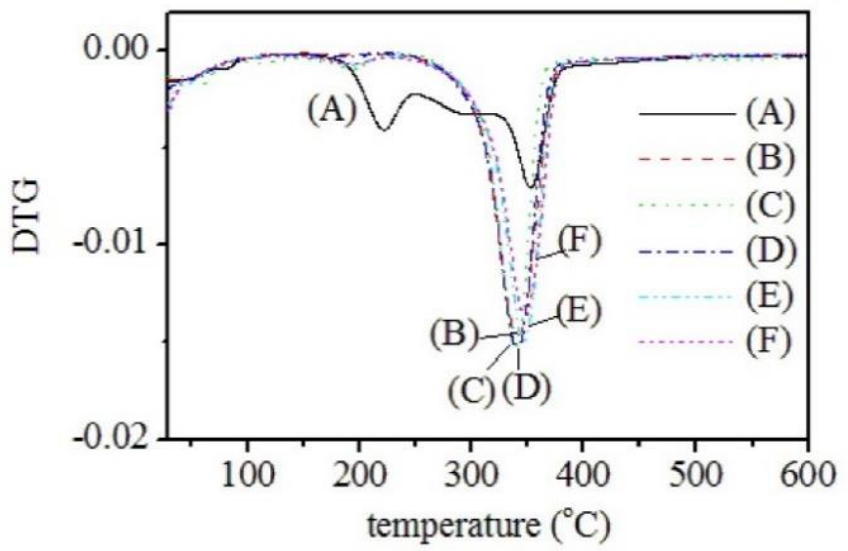

Figure 3. (a) TGA and (b) DTG curves of (1) SCB; (2) bleached cellulose, cellulose hydrolyzed with (3) $0 \%(\mathrm{w} / \mathrm{v}) \mathrm{OX}$; (4) 5\%(w/v) OX; (e) $10 \%$ (w/v) OX; and (5) 30\% (w/v) OX.

Table 2. The thermal degradation temperature $\left(\mathrm{T}_{\mathrm{d}}\right)$, the maximum degradation temperature $\left(\mathrm{T}_{\max }\right)$ and residues of $\mathrm{SCB}$, bleached cellulose and the cellulose hydrolyzed with $0,5,10$ and $30 \%(\mathrm{w} / \mathrm{v})$ oxalic acid.

\begin{tabular}{|c|c|c|c|c|c|c|c|}
\hline \multirow[t]{2}{*}{ Samples } & \multicolumn{3}{|c|}{$\begin{array}{c}T_{d} \\
\text { Thermal events }\end{array}$} & \multicolumn{3}{|c|}{$\begin{array}{c}\mathbf{T}_{\max } \\
\text { Thermal events }\end{array}$} & \multirow{2}{*}{$\begin{array}{l}\text { Residues } \\
\text { at } 600^{\circ} \mathrm{C}\end{array}$} \\
\hline & $\mathbf{1}^{\mathbf{0}}$ & $\mathbf{2}^{\mathbf{0}}$ & $3^{0}$ & $\mathbf{1}^{0}$ & $2^{0}$ & $3^{0}$ & \\
\hline SCB & 201 & 270 & 341 & 222 & 302 & 353 & $13.4 \%$ \\
\hline $\begin{array}{l}\text { bleached } \\
\text { cellulose }\end{array}$ & 183 & - & 318 & 210 & & 341 & $12.0 \%$ \\
\hline $\mathrm{HC}-0 \% \mathrm{OX}$ & 176 & - & 316 & 192 & - & 339 & $12.8 \%$ \\
\hline $\mathrm{HC}-5 \% \mathrm{OX}$ & 175 & - & 316 & 188 & - & 340 & $12.7 \%$ \\
\hline $\mathrm{HC}-10 \% \mathrm{OX}$ & 173 & - & 319 & 180 & - & 347 & $12.6 \%$ \\
\hline $\mathrm{HC}-30 \% \mathrm{OX}$ & 173 & - & 321 & 180 & - & 348 & $12.2 \%$ \\
\hline
\end{tabular}




\section{Morphology of the nanocellulose}

Figure 4 shows the FE-SEM micrographs of the cellulose fibers prepared by mechanically homogenizing bleached cellulose (a) and hydrolyzed cellulose ((b) to (e)) at 11,000 rpm for $10 \mathrm{~min}$. The size diameters of fibrils obtained from homogenizing the cellulose hydrolyzed without using oxalic acid was $167 \pm 61$ $\mathrm{nm}$, and those fibrils from the cellulose hydrolyzed with $5.0 \%, 10.0 \%$ and $30.0 \%(\mathrm{w} / \mathrm{v})$ oxalic acid were $31 \pm 12,91 \pm 33,37 \pm 13 \mathrm{~nm}$, respectively.

\section{Dispersion studies of nanocellulose}

Figure 5 shows the CNF suspension in deionized water, dimethyl formamide (DMF) and acetone. The solvents were arranged in the order of decreasing polarity. The CNF suspension in DMF started to aggregate within 3 days after sonication while that in acetone aggregated within 1 day. The suspension exhibits much better dispersibility in water, in which there was no aggregation found within the time length of our study (7 days). 

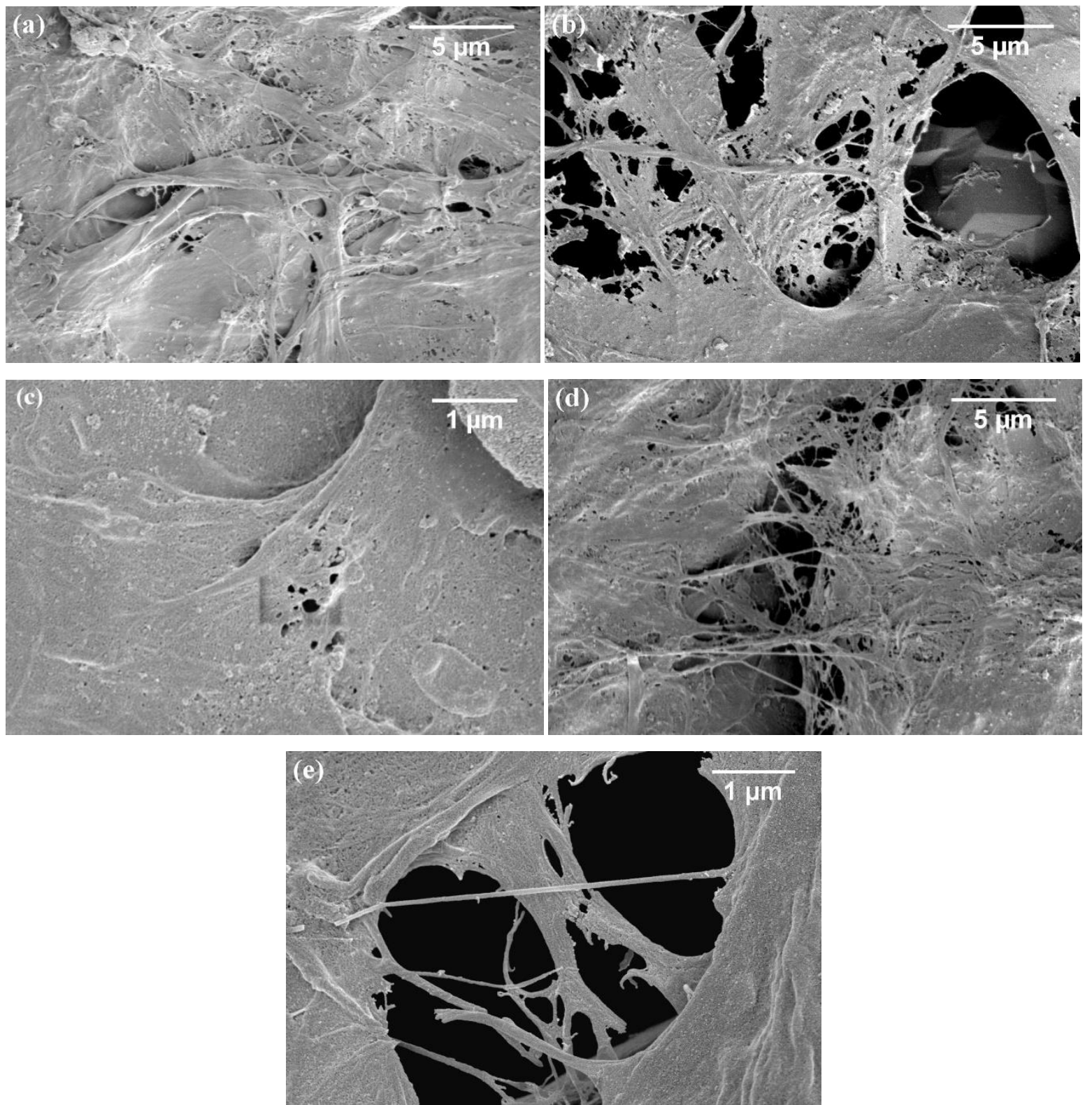

Figure 4. FE-SEM images of cellulose fibers prepared by mechanically homogenizing: (a) the bleach cellulose; and the hydrolyzed cellulose obtained by hydrothermal hydrolysis with (b) $0 \%$ OX; (c) $5 \%$ OX; (d) $10 \% \mathrm{OX}$ and (e) $30 \% \mathrm{OX}$. 


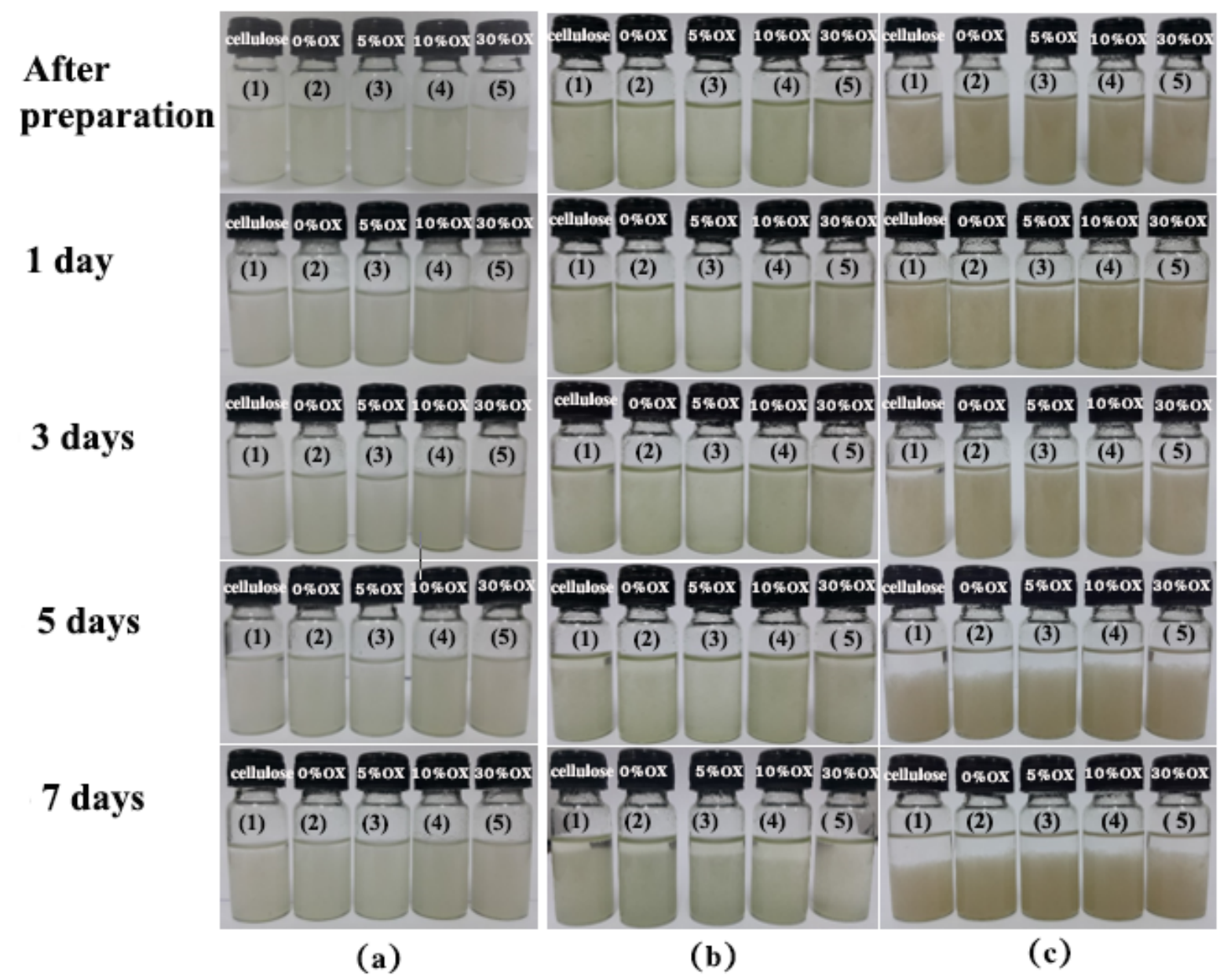

Figure 5. Pictures of dispersions of cellulose fiber prepared by homogenizing the bleached cellulose and the cellulose hydrolyzed with $0,5,10$ and $30 \%$ (w/v) oxalic acid in: (a) deionized water; (b) DMF and (c) acetone. Pictures were taken directly after preparation, 1 day, 3 days, 5 days, and 7 days after preparation.

\section{Dynamic mechanical analysis (DMA)}

The suspension of bleached cellulose and the cellulose hydrolyzed with 0 , 5,10 , and $30 \%(\mathrm{w} / \mathrm{v})$ oxalic acid were mechanically homogenized and then cast to form the films. The effect of the acid concentration on the creep properties of the obtained nanocellulose films was investigated using DMA in creep mode. The creep-testing results of the bleached cellulose and hydrolyzed cellulose (HC) membranes are shown in Figure 6. The hydrolyzed cellulose prepared without using oxalic acid (HC-0\% OX) demonstrated the highest creep rate. In contrast, creep rates of the films obtained from the hydrolyzed cellulose with $10.0 \% \mathrm{w} / \mathrm{v}$ oxalic acid ( HC- $10 \% \mathrm{OX}$ ) and that with $30.0 \% \mathrm{w} / \mathrm{v}$ oxalic acid ( $\mathrm{HC}-30 \% \mathrm{OX}$ ) were diminished. 


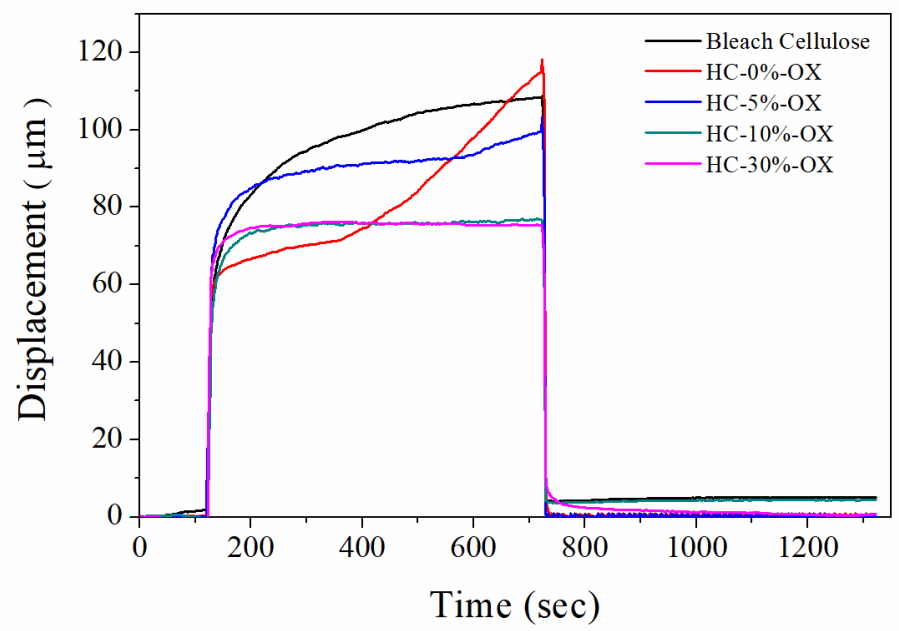

Figure 6. Creep test curves of cellulose films obtained from the bleached cellulose and the cellulose hydrolyzed with $0,5,10$, and $30 \%(\mathrm{w} / \mathrm{v})$ oxalic acid.

\section{DISCUSSION}

\section{FTIR analysis}

From FTIR spectra in Figure 1, peak at 2,910 was attributed to the C- $\mathrm{H}$ stretching, the peak at $1,640 \mathrm{~cm}^{-1}$ was attributed to the bending of the absorbed water ( Sun et al., 2004), the peak at 1,430 was assigned to $\mathrm{CH}_{2}$ symmetric bending at $\mathrm{C} 6$ of pyranose rings, the peak at 1,324 was assigned to $\mathrm{CH}_{2}$ wagging bending at $\mathrm{C} 6$, the peak at $1,062 \mathrm{~cm}^{-1}$ was assigned to $\mathrm{C}-\mathrm{O}$ stretching and $\mathrm{C}-\mathrm{O}$ deformation of C-OH (Yang et al., 2007), and the peak at $897 \mathrm{~cm}^{-1}$ was assigned to the $\beta$-1,4-glycosidic linkage between glucose unit in cellulose (Sun et al., 2004). All these peaks are common characteristics found in all studied samples. The absorption peak between 3,000 and $3,600 \mathrm{~cm}^{-1}$, which assigned to the $\mathrm{O}-\mathrm{H}$ stretching vibrations, shifted from 3,385 to $3,421 \mathrm{~cm}^{-1}$ after the SCB was treated by alkaline treatment and bleaching process. Reddy and Yang (2005) explained this blue shift as follows: alkaline treatment might reduce the concentration of hydrogen bonds by the reaction of $\mathrm{NaOH}$ and hydroxyl groups. Besides, the peaks at $1,730,1,600$ and $1,241 \mathrm{~cm}^{-1}$ corresponding to the aromatic skeletal vibration and carbonyl groups of the hemicellulose and lignin components (Abraham et al., 2013) were found only in SCB. The peak at 1,730 was assigned to the $\mathrm{C}=\mathrm{O}$ stretching of hemicellulose, the peak at $1,600 \mathrm{~cm}^{-1}$ was assigned to $\mathrm{C}=\mathrm{C}$ stretching of aromatic skeleton mode, and at $1,241 \mathrm{~cm}^{-1}$ was assigned to the $\mathrm{C}-\mathrm{O}$ stretching of phenol. The peak at $1,515 \mathrm{~cm}^{-1}$ due to the $\mathrm{C}=\mathrm{O}$ stretching of ester disappeared after bleaching with $\mathrm{NaClO}_{2}$, indicating full removal of lignin. These results confirmed that the structural linkages between lignin and carbohydrate 
were destroyed by saponification of intermolecular ester bonds; the lignin structure was disrupted by breaking its glycosidic ether bonds (Lee et al., 2014). Thus, most of the lignin polymer and hemicellulose were removed during extraction and bleaching procedures.

Similarly, hydrolyzed cellulose showed the characteristic peaks of $\alpha$ cellulose I at 3,340, 2,910, 1,640,1,430, 1,324, 1,062 and $897 \mathrm{~cm}^{-1}$ which attributed to $\mathrm{O}-\mathrm{H}$ stretching, $\mathrm{C}-\mathrm{H}$ stretching of $\mathrm{CH}_{2}$, the bending of the absorbed water, $\mathrm{CH}_{2}$ symmetric bending at $\mathrm{C} 6$ of pyranose ring, $\mathrm{CH}_{2}$ wagging bending at $\mathrm{C} 6$ of pyranose, $\mathrm{C}-\mathrm{O}$ stretching and $\mathrm{C}-\mathrm{O}$ deformation of $\mathrm{C}-\mathrm{OH}$, and the $\beta-1,4-$ glycosidic linkage between glucose units in cellulose, respectively. Once oxalic acid with concentrations of $10 \%$ and $30 \%(\mathrm{w} / \mathrm{v})$ was used in hydrolysis, the hydrolyzed fibers showed the peak at $1,730 \mathrm{~cm}^{-1}$. This peak was attributed to the $\mathrm{C}=\mathrm{O}$ of the oxalate ester. With a microwave reactor at $100^{\circ} \mathrm{C}$, oxalic acid could react with $\mathrm{OH}$ groups in cellulose. Therefore, apart from acting as the catalyst, oxalic acid with high concentrations $(10 \%$ and $30 \%(\mathrm{w} / \mathrm{v}))$ could be used for cellulose modification. The esterification of oxalic acid and hydroxyl groups of cellulose is proposed as shown in Figure 7.
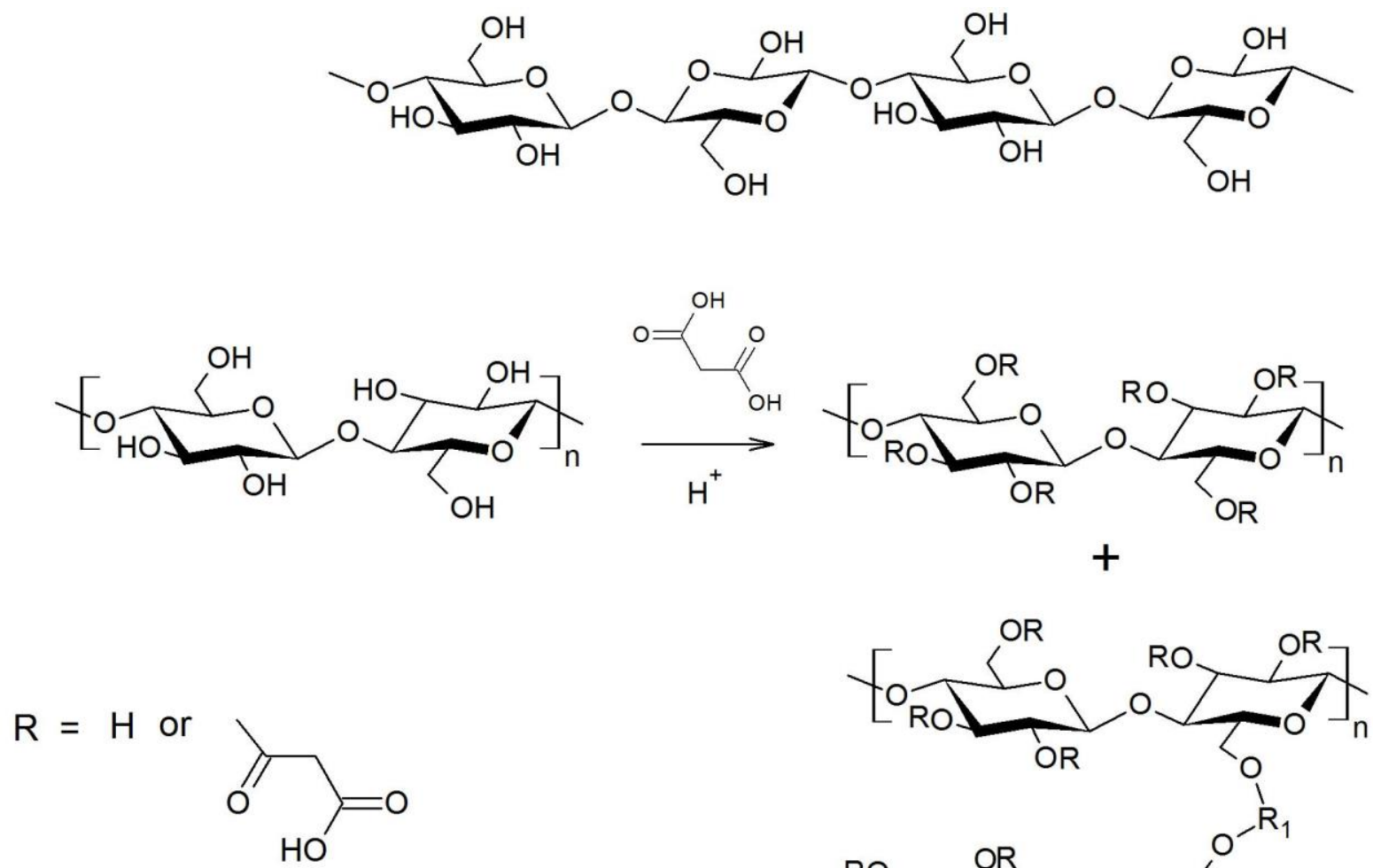<smiles>[R]=[Fe]C(C)=O</smiles>

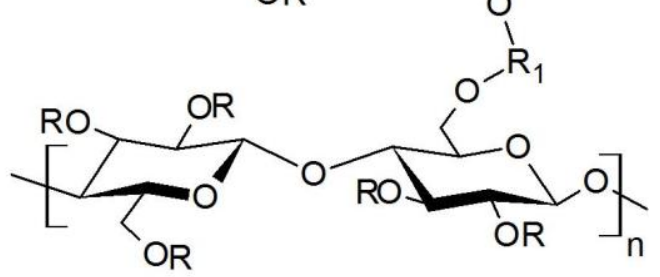

Figure 7. Esterification of oxalic acid and hydroxyl groups of cellulose. 


\section{$\%$ Yield and viscosity average molecular weight}

It was found that yield of the hydrolyzed cellulose decreased with increasing concentrations of oxalic acid. This indicated the cellulose degradation, resulting in the formation of smaller size molecules and finally glucose molecules (Chimentão et al., 2014; Lacerda et al., 2015).

The intrinsic viscosity listed in Table 1 was calculated from the Huggins equation. It is directly related to the hydrodynamic volume $\left(V_{h}\right)$ occupied by the molecules. The values depended on the size and shape of molecules in the solvent at a given temperature. The relation between molecular weight and the intrinsic viscosity is described by the Mark-Houwink-Sakurada equation (4):

$$
[\eta]=K \bar{M}_{V}^{a}
$$

$K$ and $a$ values for cellulose in $2 \% \mathrm{w} / \mathrm{w} \mathrm{LiCl} / \mathrm{DMAc}$ solution proposed by McCormick are $1.278 \times 10^{-4} \mathrm{~cm}^{3} / \mathrm{g}$ and 1.19 , respectively (McCormick and Lichatowich, 1979). The data in Table 1 show that bleached cellulose has much higher $[\eta]$ and $\bar{M}_{V}$ than the respective values for the four hydrolyzed fibers. The results indicated that the hydrothermal hydrolysis reaction, as well as mechanical homogenization, depolymerized the molecules of cellulose. Oxalic acid could act as a catalyst for hydrolysis, leading to the formation of molecules with lower degrees of polymerization. With increasing concentration of oxalic acid, [ $\eta]$ and $\bar{M}_{V}$ of hydrolyzed cellulose slightly decreased as compared to the values for the system without oxalic acid. Thus, changes in oxalic acid concentration played only a small effect on reducing the size of cellulose molecules.

\section{X-ray diffraction}

The XRD pattern of raw SCB fiber in Figure 2 shows several diffraction peaks. Two main peaks corresponding to the diffraction planes (110) and (200) of cellulose I, together with other impurities, were found on the amorphous halo. This result indicated the crystalline component of cellulose I was embedded in the amorphous matrix of lignin, hemicellulose, etc. The more ordered structure with the XRD pattern at $2 \theta=16.6^{\circ}, 22.2^{\circ}$ and $34.8^{\circ}$ was observed in the bleached cellulose (see Figure 2). These peaks corresponded to the $\left(\begin{array}{lll}1 & 1 & 0\end{array}\right),\left(\begin{array}{lll}2 & 0 & 0\end{array}\right)$ and $\left(\begin{array}{ll}0 \\ 0\end{array}\right.$ $04)$ respectively. The crystallinity index ( CrI) of bleached cellulose was improved significantly by the chemical treatment. The values were at $36.7 \%$ and $55.4 \%$ for SCB and bleached cellulose, respectively. This result confirmed that hemicellulose and lignin as amorphous matrix have reacted with $\mathrm{NaOH}$ and were fully destroyed by saponification during the alkali and sodium chlorite pretreatments (Abraham et al., 2013; Lee et.al., 2014 ).

Similar to that of the bleached cellulose, the XRD patterns of hydrolyzed cellulose ( see Figure 2) at $2 \theta$ of about $16.6^{\circ}, 22.4^{\circ}$ and 35.0 indicated the $\alpha$ cellulose I structure. However, the peak intensity was found to increase as 
compared with the bleached cellulose. The crystallinity index (CrI) quantified the $\%$ crystallinity are shown in Table 3 . CrI values for hydrolyzed celluloses were higher than that for the bleached cellulose. The results reflected the removal of the amorphous components of the cellulose after hydrolysis. The crystallinity of hydrolyzed cellulose prepared when using 5\% oxalic acid as a catalyst was only insignificantly different as compared to the hydrolyzed cellulose prepared without oxalic acid. A similar result was reported by Chimentão et al. (2014). They reported that oxalic acid enhanced the crystallinity of cellulose, but no significant change was observed when increasing the content of oxalic acid from $3 \%$ to $6 \%$. The increase in CrI was found in our work when using $10 \%$ oxalic acid. However, with further increasing oxalic acid concentration to $30 \%$, the $\mathrm{CrI}$ remained unchanged. To investigate the effect of the oxalic concentration on the size of crystalline domains, the crystallite size, $t$, determined perpendicular to the (200) plane was estimated using equation (3). The values are given in Table 3. It was found that the crystallite sizes of hydrolyzed cellulose increase as compared with the bleached cellulose. The increase of the crystallite size could be explained by the consumption of the amorphous region, resulting in the coalescence of smaller crystalline domains during hydrolysis (Lacerda et al., 2015). With further increasing concentration of oxalic acid to $10 \%(\mathrm{w} / \mathrm{v})$ and $30 \%(\mathrm{w} / \mathrm{v})$, however, a slight reduction of the crystallite size was observed.

Table 3. Crystallinity index (CrI) and crystallite size (t) of bleached and hydrolyzed cellulose obtained by hydrothermal hydrolysis with various concentrations of oxalic acid.

\begin{tabular}{lccccc}
\hline Samples & $\begin{array}{c}\text { Bleached } \\
\text { cellulose }\end{array}$ & HC-0\% OX & HC-5\% OX & HC-10\% OX & HC-30\% OX \\
\hline $\begin{array}{l}\text { CrI } \\
(\%)\end{array}$ & 55.5 & 59.3 & 58.9 & 63.1 & 62.9 \\
$\mathbf{t}(\AA)$ & 25.9 & 33.0 & 33.2 & 31.7 & 31.0 \\
\hline
\end{tabular}

\section{Thermogravimetric analysis}

In Figure 3(a), SCB shows three stages of decomposition. The initial decomposition started at $200^{\circ} \mathrm{C}$, resulting from the release of moisture and volatile matters. The maximum weight loss of this stage was found in DTG (Figure $3(\mathrm{~b})$ ) at $222^{\circ} \mathrm{C}$. Besides that peak, the SCB curve shows a maximum peak at $353^{\circ} \mathrm{C}$ along with the shoulder peak at about $302^{\circ} \mathrm{C}$, corresponding to $\alpha$ cellulose and hemicelluloses, respectively. Indeed, the decomposition range of SCB covers a wide temperature range from 200 to $500^{\circ} \mathrm{C}$ due to the presence of lignin. Abraham et al. (2013) reported that the thermal decomposition of lignin began at $270^{\circ} \mathrm{C}$ and continued until $500^{\circ} \mathrm{C}$. The wide range of temperature 
decomposition was attributed to the different activities of the chemical bonds present in the lignin structure (Klemm et al., 2004).

The degradation behaviors of bleached cellulose and hydrolyzed celluloses were similar. Two thermal events were observed in the range of 150$200^{\circ} \mathrm{C}$ and $300-380^{\circ} \mathrm{C}$. The initial step was attributed to the devolatilization process of moisture or low molecular weight compounds. Due to weaker hydrogen bonds between fibrils of bleached and hydrolyzed celluloses, the devolatilization peak shifted to a lower temperature as compared with that of SCB. The degradation step due to the decomposition of hemicellulose was absent. The main event of weight loss observed between $300^{\circ} \mathrm{C}$ and $380^{\circ} \mathrm{C}$ was the decomposition of $\alpha$-cellulose. Thus the thermal stabilities of bleached cellulose and hydrolyzed cellulose were enhanced as compared to the SCB. These results were attributed to the removal of the easily degradable components such as hemicellulose and lignin. However, the $T_{d}$ and $T_{\max }$ of bleached cellulose and hydrolyzed celluloses are much lower than those of $\alpha$-cellulose embedded in $\mathrm{SCB}$. These results may be mainly due to the removal of the strong lignincellulose complex in SCB during the pretreatment.

Additionally, the solid residue left after pyrolysis at $600^{\circ} \mathrm{C}$ (see Table 2) of SCB was higher than those of bleached and hydrolyzed celluloses. This result could be attributed to the aromatic nature of the lignin complexes (Abraham et al., 2013). From TGA and DTG curves, no significant difference was found among bleached cellulose and hydrolyzed celluloses obtained from hydrolysis with 0 and $5 \% \mathrm{w} / \mathrm{v}$ oxalic acid. With further increasing acid concentration to $10 \%$ and to $30 \%$, however, the $T_{d}$ and $T_{\max }$ of hydrolyzed cellulose due to the $\alpha$ cellulose component increased slightly (see Table 2). These results indicate that oxalic acid at relatively high concentrations affects the thermal degradation of hydrolyzed cellulose. The increasing amount of organic components (oxalate groups) containing in the cellullose molecules compensated with the increasing amount of crystallinity after hydrothermally hydrolyzing cellulose with higher levels of oxalic acid $(10 \%$ and $30 \%(w / v))$.

\section{Morphology of the nanocellulose}

It was found SEM micrographs in Figure 4 that untreated bleached cellulose without hydrolysis shows a broader range of diameters. Strong intermolecular H-bonding between the cellulose chains was important here. After hydrothermal hydrolysis, the fibers could be disintegrated by mechanical homogenization. The obtained nanofibers are well separated and show a weblike network corresponding to the cellulose nanofiber (CNF) type of the nanocellulose. It was found that fibers from hydrolyzed cellulose can be disintegrated more easily by the homogenizer than fibers from bleached cellulose. With $5 \%(\mathrm{w} / \mathrm{v})$ oxalic acid, the size of the CNF obtained was smallest $(31 \pm 12 \mathrm{~nm})$. 


\section{Dispersion studies of nanocellulose}

The dispersion of nanocellulose is of critical importance for its successful preparation. It could be seen in Figure 5 that CNFs prepared from different concentrations of oxalic acid were well dispersed in water, DMF and acetone right after sonication. These results were attributed to high hydrophilicity and the repulsion of oxalate ions on the surfaces of CNFs. In Figures 5(a(1 day) to 5(c) 1 day)), suspension prepared from bleached cellulose started to aggregate fastest among other hydrolyzed celluloses, especially in acetone where the instability was found in one day after sonication. The dispersion stability of the suspension in both organic solvents (DMF and acetone) increased with increasing concentrations of oxalic acid used in the hydrolysis. This could be due to larger numbers of oxalate groups on the surfaces of CNFs.

\section{Dynamic mechanical Analysis (DMA)}

The first region of the curve in Figure 6 corresponded to the stage of unapplied loading. The creep deformation and recovery behavior were observed in the second and third regions, respectively. It was found that the initial displacement at the same applied stress of all films was similar. However, the films obtained from bleached cellulose, from the hydrolyzed cellulose prepared without using oxalic acid ( $\mathrm{HC}-0 \% \mathrm{OX})$ and the hydrolyzed cellulose prepared with $5.0 \% \mathrm{w} / \mathrm{v}$ oxalic acid $(\mathrm{HC}-5 \% \mathrm{OX})$ showed viscoelastic response. The creep deformation of cellulose film slightly increased as time increased. The film obtained from $\mathrm{HC}-0 \% \mathrm{OX}$ exhibited the highest creep rate (slope of the plot in the second region). In contrast, the elastic response was found when the cellulose was hydrolyzed with high concentrations of oxalic acid ( $\mathrm{HC}-10 \% \mathrm{OX}$ and $\mathrm{HC}-30 \% \mathrm{OX}$ ). A lower molecular weight, as well as a higher degree of crystallinity of the $\mathrm{HC}-10 \% \mathrm{OX}$ and the $\mathrm{HC}-30 \% \mathrm{OX}$ could be explained this phenomenon. In the third region (creep recovery region) the displacement of all samples, except homogenized bleached cellulose and the $\mathrm{HC}-10 \% \mathrm{OX}$, were almost fully recovered after the load was removedindicating the elastic behavior of the films.

\section{CONCLUSION}

The effects of oxalic acid concentration used in cellulose hydrothermally microwave-assisted hydrolysis were investigated. Oxalic acid could act as a catalyst for hydrolysis. The acid could attack and depolymerize cellulose chains to produce molecules with lower degrees of polymerization. Moreover, when using oxalic acid with concentrations of $10 \%$ or higher, esterification of oxalic acid and hydroxyl groups of cellulose took place. However, changes in oxalic acid concentration played only a small effect on reducing the size of cellulose molecules. The crystallinity of hydrolyzed cellulose was slightly higher if oxalic 
acid with concentrations higher than $5 \%$ was used. The thermal stability of cellulose hydrolyzed by oxalic acid might depend on a compromise of the reduction of H-bonding between the cellulose fibers and the presence of oxalate groups as well as an increase in crystallinity. It was found that fibers from hydrolyzed cellulose can be disintegrated more easily by the homogenizer than fibers from bleached cellulose. The nanofibers from hydrolyzed cellulose prepared using oxalic acid as a catalyst were well separated and showed a weblike network structure. Owing to oxalate groups present on the molecular chains, the dispersion stability of the CNFs suspension in organic solvents (here DMF and acetone) could be enhanced if high concentrations of oxalic acid (10 and 30\% $\mathrm{w} / \mathrm{v}$ ) were used in the hydrolysis reaction. The creep resistance of the cellulose films obtained from the cellulose hydrolyzed with high concentrations of oxalic acid (10 and $30 \% \mathrm{w} / \mathrm{v})$ was found. With the concentrations of $10 \% \mathrm{w} / \mathrm{v}$ or higher, oxalic acid was found as a promising catalyst for concurrent reactions, including cellulose hydrolysis and surface modification of cellulose with carboxyl functional groups.

\section{ACKNOWLEDGEMENTS}

The authors would like to express the appreciations to Department of Chemistry, Faculty of Science, KMUTT for financial support and to Faculty of Science, KMUTT for providing the scholarship to two of us (T.W. and A.R)

\section{REFERENCES}

Abraham, E., Deepa, B., Pothen, L.A., Cintil, J., Thomas, S., John, M.J., Anandjiwala, R., and Narine, S.S. 2013. Environmental friendly method for the extraction of coir fibre and isolation of nanofibre. Carbohydrate. Polymer. 92(2): 1477-1483. https://doi.org/10.1016/j.carbpol.2012.10.056 Brostow, W., and Hagg Lobland, H. E. 2017. Materials: Introduction and applications. New York: John Wiley \& Sons.

Chen, L., Zhu, J. Y., Baez, C., Kitin, P., and Elder, T. 2016. Highly thermalstable and functional cellulose nanocrystals and nanofibrils produced using fully recyclable organic acids. Green Chemistry 18: 3835- 3843. https://doi.org/10.1039/C6GC00687F

Chen, W.-H., Ye, S.-C., and Sheen, H.-K. 2012. Hydrolysis characteristics of sugarcane bagasse pretreated by dilute acid solution in a microwave irradiation environment. Applied Energy. 93: 237-244. https://doi.org/ 10.1016/j.apenergy.2011.12.014 
Cherian, B.M., Leão, A.L., de Souza, S.F., Thomas, S., Pothan, L. A., and Kottaisamy, M. 2010. Isolation of nanocellulose from pineapple leaf fibres by steam explosion. Carbohydrate Polymers. 81: 720-725. https://doi.org/ 10.1016/j.carbpol.2010.03.046

Chimentão, R. J., Lorente, E., Gispert-Guirado, F., Medina, F., and López, F. 2014. Hydrolysis of dilute acid- pretreated cellulose under mild hydrothermal conditions. Carbohydrate Polymers. 111: 116-124. https://doi.org/10.1016/j.carpol.2014.04.001

Cui, S., Zhang, S., Ge, S., Xiong, L., and Sun, Q. 2016. Green preparation and characterization of size-controlled nanocrystalline cellulose via ultrasonicassisted enzymatic hydro-lysis. Industrial Crops and Products. 83: 346352. https://doi.org/10.1016/j.indcrop.2016.01.019

Dahlem, M. A., Borsoi, C., Hansen, B., and Catto, A. L. 2019. Evaluation of different methods for extraction of nanocellulose from yerba mate residues. Carbohydrate Polymers. 218: 78-86. https://doi. org/10.1016/j. carbpol. 2019.01.064

Deepa, B., Abraham, E., Cherian, B.M., Bismarck, A., Blaker, J.J., Pothan, L.A., Leao, A. L., de Souza, S. F., and Kottaisamy, M. 2011. Structure, morphology and thermal characteristics of banana nano fibers obtained by steam explosion. Bioresource Technology. 102: 1988-1997. https:// doi.org/10.1016/j.biortech.2010.09.030

Du, H., Liu, C., Zhang, Y., Yu, G., Si, C., and Li, B. 2016. Preparation and characterization of functional cellulose nanofibrils via formic acid hydrolysis pretreatment and the followed high-pressure homogenization. Industrial Crops and Products 94: 736-745. https:// doi.org/10. 1016/ j.indcrop.2016.09.059

Espinosa, S.E., Kuhnt, T., Foster E.J., and Weder, C. 2013. Isolation of thermally stable cellulose nanocrystals by phosphoric acid hydrolysis. Biomacromolecules. 14(4): 1223-1230. https://doi.org/10.1021/bm400219u

Ferrer, A., Filpponen, I., Rodríguez, A., Laine, J., and Rojas, O. J. 2012. Valorization of residual Empty Palm Fruit Bunch Fibers (EPFBF) by microfluidization: Production of nanofibrillated cellulose and EPFBF nanopaper. Bioresource Technology. 125: 249-255. https:// doi. org/ 10.1016/j.biortech.2012.08.018

Hafraoui, S. E., Nishiyama, Y., Putaux, J.-L., Heux, L., Dubreuil, F., and Rochas, C. 2008. The shape and size distribution of crystalline nanoparticles prepared by acid hydrolysis of native cellulose. Biomacromolecules. 9: 57-65. https://doi.org/10.1021/bm700769p 
Klemm, D., Philipp, B., Heinze, T., Heinze, U., and Wagenknecht, W. 2004. General considerations on structure and reactivity of cellulose: Section 2.42.4.3. In: Klemm, D., Philipp, B., Heinze, T., Heinze, U., and Wagenknecht, W., editors. Comprehensive Cellulose Chemistry. Weinheim: Wiley-VCH Verlag. pp. 130-165.

Kusumattaqiin, F., and Chonkaew, W. 2015. Preparation and characterization of microcrystalline cellulose (MCC) by acid hydrolysis using microwave assisted method from cotton wool. Macromolecular Symposia. 354: 3541. https://doi.org/10.1002/MASY.2014-00110

Lacerda, T.M., Zambon, M.D., and Frollini, E. 2015. Oxalic acid as a catalyst for the hydrolysis of sisal pulp. Industrial Crops and Products. 71: 163-172. https://doi.org/10.1016/j.indcrop.2015.03.072

Lee, H.V., Hamid, S.B.A., and Zain, S.K. 2014. Conversion of lignocellulosic biomass to nanocellulose: structure and chemical process. Scientific. World Journal. 2014: 1-20. https://doi.org/10.1155/2014/631013

Lee, S.-Y., Chun, S.-J., Kang, I.-A., and Park, J.-Y. 2009. Preparation of cellulose nanofibrils by high-pressure homogenizer and cellulose-based composite films. Journal of Industrial and Engineering Chemistry. 15(1): 50-55. https://doi.org/10.1016/j.jiec.2008.07.008

Li, B., Xu, W., Kronlund, D., Määttänen, A., Liu, J., Smått, J.-H., Peltonen, J., Willför, S., Mu, X., and Xu, C. 2015. Cellulose nanocrystals prepared via formic acid hydrolysis followed by TEMPO- mediated oxidation. Carbohydrate Polymers. 133: 605-612. https://doi.org/10.1016/jcarbpol. 2015.07.033

Li, J., Wei, X., Wang, Q., Chen, J., Chang, G., Kong, L., Su, J., and Liu, Y. 2012. Homogeneous isolation of nanocellulose from sugarcane bagasse by high pressure homogenization.Carbohydrate Polymers. 90(4): 1609-1613. https://doi.org/10.1016/j.carbpol.2012.07.038

Liu, C., Li, B., Du, H., Lv, D., Zhang, Y., Yu, G., Mu, X. and Peng, H. 2016. Properties of nanocellulose isolated from corncob residue using sulfuric acid, formic acid, oxidative and mechanical methods. Carbohydrate Polymers. 151: 716-724. https://doi.org/10.1016/j.carbpol.2016.06.025

Liu, J., Zhang, J., Zhang, B., Zhang, X., Xu, L., Zhang, J., He, J., and Liu, C.-Y. 2016. Determination of intrinsic viscosity-molecular weight relationship for cellulose in BmimAc/DMSO solutions. Cellulose. 23: 2341-2348. https://doi.org/10.1007/s10570-016-0967-1

Liu, Y., Wang, H., Yu, G., Yu, Q., Li, B., and Mu, X. 2014. A novel approach for the preparation of nanocrystalline cellulose by using phosphotungstic acid. Carbohydrate Polymers. 110: 415-422. https://doi.org/10.1016/ j.carbpol.2014.04.040 
Lu, H., Gui, Y., Zheng, L., Liu, X. 2013. Morphological, crystalline, thermal and phy-sicochemical properties of cellulose nanocrystals obtained from sweet potato residue. Food Research International. 50(1): 121-128. https://doi. org/10.1016/j.foodres.2012.10.013

Lu, P., and Hsieh, Y. - L. 2010. Preparation and properties of cellulose nanocrystals: Rods, spheres, and network. Carbohydrate Polymers. 82(2): 329-336. https://doi.org/10.1016/j.carbpol.2010.04.073

Lu, Z., Fan, L., Zheng, H., Lu, Q., Liao, Y., and Huang, B. 2013. Preparation, characterization and optimization of nanocellulose whiskers by simultaneously ultrasonic wave and microwave assisted. Bioresource. Technology. 146: 82-88. https://doi.org/10.1016/j.biortech.2013.07.047

Lv, D., Du, H., Che, X., Wu, M., Zhang, Y., Liu, C., Nie, S., Zhang, X., and $\mathrm{Li}, \mathrm{B}$. 2019. Tailored and integrated production of functional cellulose nanocrystals and cellulose nanofibrils via sustainable formic acid hydrolysis: kinetic study and characterization. ACS Sustainable Chemistry \& Engineering 7: 9449-9463.

Mandal, A., and Chakrabarty, D. 2011. Isolation of nanocellulose from waste sugarcane bagasse (SCB) and its characterization. Carbohydrate Polymers. 86: 1291-1299. https://doi.org/10.1016/j.carbpol.2011.06.030

Masruchin, N., Park, B.-D., and Causin, V. 2015. Influence of sonication treatment on supramolecular cellulose microfibril- based hydrogels induced by ionic interaction. Journal of Industrial and Engineering Chemistry. 28: 265-272.

McCormick, C.L., and Lichatowich, D.K. 1979. Homogenous solution reactions of cellulose, chitin and other polysaccharides to produce controlledactivity pesticide systems. Journal of Polymer Science: Polymer Letters Edition.17: 479-484.

McCrackin, F.L. 1987. Relationship of intrinsic viscosity of polymer solutions to molecular weight. Polymer. 28: 1847-1850. https://doi.org/10.1016/ 0032-3861(87)90289-8

Ongthip L., and Chonkaew,W. 2018. Nanofibrillar cellulose from Para Rubber Wood Sawdust as reinforcement in Polylactic Acid Composites. Srinakharinwirot Science Journal. 34(1): 264-275.

Pereira, A.L. S., Nascimento, D. M.D., Souza Filho, M.d.s. M., Morais, J.P.S., Vasconcelos, N.F., Feitosa, J.P.A., Brígida, A.I.S., and Rosa, M.d.F. 2014. Improvement of polyvinyl alcohol properties by adding nanocrystalline cellulose isolated from banana pseudostems. Carbohydrate Polymers. 112: 165-172. https://doi.org/10.1016/j.carbpol.2014.05.090

Reddy, N., and Yang, Y. 2005. Structure and properties of high quality natural cellulose fibers from cornstalks. Polymer. 46(15): 5494-5500. https://doi. org/10.1016/j.polymer.2005.04.073 
Soni, B., Hassan, E.B., and Mahmoud, B. 2015. Chemical isolation and characterization of different cellulose nanofibers from cotton stalks. Carbohydrate Polymers. 134: 581-589. https://doi.org/10.1016/j.carbpol. 2015.08.031

Sun, J.X, Sun, X.F, Zhao, H., and Sun, R.C. 2004. Isolation and characterization of cellulose from sugarcane bagasse. Polymer Degradation and Stability. 84(2): 331-339. https://doi.org/10.1016/j.polymdegradstab.2004.02.008

Segal, L., Creely, J., Martin, A., and Conrad, C. 1959. An empirical method for estimating the degree of crystallinity of native cellulose using the $\mathrm{x}$-ray diffractometer. Textile Research Journal. 29: 786-794. https:// doi.org/ $10.1177 / 004051755902901003$

Wang, Y., Wei, X., Li, J., Wang, F., Wang, Q., Chen, J., Kong, L. 2015. Study on nanocellulose by high pressure homogenization in homogeneous isolation. Fiber. Polymer. 15: 572-578.

Xu, W., Grénman, H., Liu, J., Kronlund, D., Li, B., Backman, P., Peltonen, J., Willför, S., Sundberg, A., and Xu, C. 2017. Mild oxalic-acid-catalyzed hydrolysis as a novel approach to prepare cellulose nanocrystals. ChemNanoMat. 3(2): 109-119. https://doi.org/10.1002/cnma.201600347

Yang, H., Yan, R., Chen, H., Lee, D.H., and Zheng, C. 2007. Characteristics of hemicellulose, cellulose and lignin pyrolysis. Fuel. 86: 1781- 1788. https://doi.org/10.1016/j.fuel.2006.12.013

Zeni, M., Favero, D., Pacheco, K., and Grisa, A.M.C. 2015. Preparation of microcellulose (mcc) and nanocellulose (ncc) from eucalyptus krafts pulp. Polymer Science. 1: 1-5. https://doi.org/10.4172/2471-9935.100007 